University of Wollongong

Research Online

Faculty of Engineering and Information

Faculty of Engineering and Information

Sciences - Papers: Part B

Sciences

2017

\title{
Ultra Wideband Channel Coefficient Measurements for Detecting Methane Gas in a Multipath Environment
}

\author{
Ahmed Moftah Ownalla Alshabo \\ University of Wollongong, amoa813@uowmail.edu.au \\ David Stirling \\ University of Wollongong, stirling@uow.edu.au \\ Montserrat Ros \\ University of Wollongong, montse@uow.edu.au \\ Peter James Vial \\ University of Wollongong, peterv@uow.edu.au \\ Beata J. Wysocki \\ University of Nebraska, bjw@uow.edu.au
}

See next page for additional authors

Follow this and additional works at: https://ro.uow.edu.au/eispapers1

Part of the Engineering Commons, and the Science and Technology Studies Commons

Research Online is the open access institutional repository for the University of Wollongong. For further information contact the UOW Library: research-pubs@uow.edu.au 


\title{
Ultra Wideband Channel Coefficient Measurements for Detecting Methane Gas in a Multipath Environment
}

\author{
Abstract \\ In this paper, an investigation was carried out into the effect of a non-explosive methane gas mixture on \\ various Ultra Wide Band Channel Coefficients. Using simplified apparatus consisting of a rubberized tube \\ ( $6 \mathrm{~mm}$ diameter) connected for significant periods to either a (pressurized) source of mixed Methane and \\ Nitrogen or alternatively to a Nitrogen only source. The tube containing either gas feed was wrapped \\ using two complete turns around a $160 \mathrm{~mm}$ diameter PVC pipe. Several flows of the mixed gas, containing \\ $2.57 \%$ methane, were introduced and flowed through the pipe before being sealed in the tube. Removal of \\ any Methane in the tube was achieved by flushing it with the pure Nitrogen source, initially and in-between \\ samples of the mixed source. A Vector Network Analyser was connected using two identical directional \\ antennas with the wrapped section of tubing placed between the two antennas and the wireless channel \\ coefficients were measured over the Ultra Wide Band frequency span of $0.3 \mathrm{GHz}$ to $8 \mathrm{GHz}$. Magnitude \\ differences were taken between the baseline condition (tube flushed out with Nitrogen) and alternatively \\ containing the methane mixture. It was found that consistent and repeatable experiments produced the \\ same trend of differences over the same frequency span. This system based on this approach could thus \\ be used as a simple sensor to detect the acc

\section{Disciplines} \\ Engineering | Science and Technology Studies

\section{Publication Details} \\ A. Alshabo, D. Stirling, M. Ros, P. James. Vial, B. Joanna. Wysocki, T. Antoni. Wysocki \& N. Dal Sasso, \\ "Ultra Wideband Channel Coefficient Measurements for Detecting Methane Gas in a Multipath \\ Environment," Australian Journal of Electrical and Electronics Engineering, vol. 13, (3) pp. 195-199, 2016.
}

\section{Authors}

Ahmed Moftah Ownalla Alshabo, David Stirling, Montserrat Ros, Peter James Vial, Beata J. Wysocki, Tadeusz A. Wysocki, and Nicholas Dal Sasso 


\title{
Ultra Wideband Channel Coefficient Measurements for Detecting Methane Gas in a Multipath Environment
}

\begin{abstract}
Ahmed Alshabo, is PhD student with the University of Wollongong, School of Electrical, Computer and Telecommunications Engineering in the Faculty of Engineering and Information Sciences, Australia

David Stirling is Senior lecturer with the University of Wollongong, School of Electrical, Computer and Telecommunication Engineering in the faculty of Engineering and Information Sciences, Australia

Montserrat Ros is Senior lecturer with the University of Wollongong, School of Electrical, Computer and Telecommunications Engineering in the Faculty of Engineering and Information Sciences, Australia
\end{abstract}

Peter Vial is Lecturer with the University of Wollongong, School of Electrical, Computer and Telecommunications Engineering in the Faculty of Engineering and Information Sciences, Australia

Beata Wysocki is Lecturer with the University of Nebraska-Lincoln, USA

Tadeusz Wysocki is Professor with the University of Nebraska-Lincoln, USA

Nicholas Dal Sasso is Engineer with ecotech Environmental Monitoring Solutions, NSW, Australia

\begin{abstract}
In this paper, an investigation was carried out into the effect of a non-explosive methane gas mixture on various Ultra Wide Band Channel Coefficients. Using simplified apparatus consisting of a rubberized tube (6 $\mathrm{mm}$ diameter) connected for significant periods to either a (pressurized) source of mixed Methane and Nitrogen or alternatively to a Nitrogen only source. The tube containing either gas feed was wrapped using two complete turns around a $160 \mathrm{~mm}$ diameter PVC pipe. Several flows of the mixed gas, containing $2.57 \%$ methane, were introduced and flowed through the pipe before being sealed in the tube. Removal of any Methane in the tube was achieved by flushing it with the pure Nitrogen source, initially and in-between samples of the mixed source. A Vector Network Analyser was connected using two identical directional antennas with the wrapped section of tubing placed between the two antennas and the wireless channel coefficients were measured over the Ultra Wide Band frequency span of $0.3 \mathrm{GHz}$ to $8 \mathrm{GHz}$. Magnitude differences were taken between the baseline condition (tube flushed out with Nitrogen) and alternatively containing the methane mixture. It was found that consistent and repeatable experiments produced the same trend of differences over the same frequency span. This system based on this approach could thus be used as a simple sensor to detect the accumulation of methane gas in an environment well before it becomes explosive at around a concentration of $5 \%$.
\end{abstract}

Index Terms - Vector Network Analyzer (VNA), Methane Gas, Ultra WideBand, Channel Coefficients, directional antennas 


\section{INTRODUCTION}

Previous studies have shown that gases, solids and liquids affect the electromagnetic wireless channel coefficients measured at individual frequencies (Alshabo et al, 2012; Baghdady and Ely, 1966; Boan, 2007; Selmic et al, 2010; Shimomura et al, 2012; Wee et al, 2009; Yin-Chung and Porter, 1978; Micheli et al, 2015). Vector Network Analyzers (VNA) are used with antennas to measure a range of complex wireless channel coefficients at many different frequencies. This is accomplished after the system has been calibrated for the effects of the antenna cabling using the TRL calibration technique (Alshabo et al, 2013).

Methane is detectable using Infrared sources and very sensitive equipment, which require expensive sensors (Leis et al, 2014). It would be advantageous to use lower frequencies to measure the presence or absence of methane below concentration levels of 5\%, where explosions can occur. Such a system would have lower production costs, using microwave frequencies compared to the infrared-based system.

Maryott et al. investigated the microwave absorption of methane, inconclusively, using equipment in the 1950's (Maryott and Birnbaum, 1956). These microwave absorption measurements are difference to the measurement of complex wireless channel coefficients measurement provided by the VNA. In addition, the measurements described in this study were obtained at pressures close to one atmosphere, a humidity of $69 \%$ and temperature varying between 24-25 degrees inside a laboratory. Microwave absorption of methane gas was identified in the atmospheres of the outer planets by Maryott et al. (Maryott and Birnbaum, 1956). The authors also suggested that the small dipole moment of methane provides stronger transitions over the microwave frequency range at atmospheric temperature. Table 1 shows the line intensities and spectral line position for frequency absorption in the atmosphere of the outer planet at temperatures of $134^{\circ} \mathrm{K}$ as observed by Maryott et al. in (Maryott and Birnbaum, 1956).

TABLE.1 LINE INTENSITIES AND SPECTRAL LINE POSITION FOR FREQUENCY ABSORPTION IN THE ATMOSPHERE [6].

\begin{tabular}{|c|c|}
\hline Frequency in $\mathrm{GHz}$ & Absolute intensity $\left(\mathrm{cm}^{-2}\right.$ amagat $\left.^{-1}\right)$ \\
\hline 1.562879 & $1.62 \mathrm{e}-12$ \\
\hline 1.791730 & $1.31 \mathrm{e}-12$ \\
\hline 2.546742 & $1.52 \mathrm{e}-12$ \\
\hline 2.688583 & $1.5 \mathrm{e}-12$ \\
\hline 2.774606 & $5.07 \mathrm{e}-12$ \\
\hline 3.946940 & $1.68 \mathrm{e}-12$ \\
\hline 4.599229 & $3.14 \mathrm{e}-12$ \\
\hline 5.014758 & $4.44 \mathrm{e}-12$ \\
\hline 5.169506 & $2.77 \mathrm{e}-12$ \\
\hline 6.940206 & $1.62 \mathrm{e}-12$ \\
\hline 7.468747 & $2.38 \mathrm{e}-12$ \\
\hline
\end{tabular}

A Broadband microwave gas sensor was proposed by Rossignol et al. (Rossignol et al, 2010) using a VNA in the frequency range $0.015 \mathrm{GHz}$ to $3 \mathrm{GHz}$ for the absorption in a metal oxide substrate connected to a coaxial line, in order to detect changes in the sensor. This is a generic technique that used the $S_{11} \mathrm{~S}$-parameter measurements of the VNA. In our study, we measure the $S_{21} S$-parameter measurements of the VNA for the wireless complex channel coefficients. 
Methane gas is an important greenhouse gas which is emitted around the world and recently increased by industry and agriculture sources (United State Environmental Protection Agency, 2010). We introduce a new technique to estimate and detect a methane gas using UWB channel measurements. This technique could be used in the mining industry. This study is new and novel as no study has been found which investigates the detection of methane gas over UWB frequency band using a vector network analyser.

This paper outlines wireless channel measurements with incorporation of a calibration and baseline measurement that allows for the detection of methane within in a small rubber tube. These measurements were conducted using a $160 \mathrm{~mm}$ diameter coil of the rubber tubing which yielded measurable and proportional differences in magnitudes between the case where a concentration of $2.57 \%$ methane in nitrogen gas was present and alternatively the baseline measurements which were taken when only nitrogen gas was present.

\section{APPARATUS}

The experiments were conducted at the University of Southern Queensland using a $0.3 \mathrm{GHz}$ to $8 \mathrm{GHz}$ VNA. For the experiments described in this paper we used nitrogen and methane gas bottles. The pressurized methane gas bottle contained a gaseous mixture of $2.57 \%$ methane with nitrogen. In addition an in-line methane sensor (4-20mA) confirmed the presence or absence of methane gas in the tube. This was constantly monitored and additional gas injected when the initial sensor measurement started to decrease below $11 \mathrm{~mA}$ (values of $4 \mathrm{~mA}$ were indicative of no methane gas present, and 10-12mA signaled the presence of methane).

Although the atmosphere is mainly composed of nitrogen gas (about 78\%), a pure pressurized nitrogen source was utilized to purge or flush any moisture or residual methane trace out of the rubber tube. The outflow of the rubber tube, connected to a pressurized gas source, was ultimately vented into the atmosphere through an external window. The rubber tubing was wrapped with two full turns around a $160 \mathrm{~mm}$ PVC support pipe. This tube was then manually connected to either the nitrogen or methane pressurized vessels. Two identical directional antennas were connected to the VNA and the system was calibrated using the TRL calibration technique outlined in(Alshabo et al, 2013). Figure 1 and Figure 2 show photographs of the experimental setup. Methane gas with a concentration level of $2.57 \%$ was subsequently injected in the rubber tube. Further, as each frequency band was changed, a new baseline was measured. The baseline was measured after flushing the previous sample of methane gas and any moisture out of the rubber tubing using the pure nitrogen source.

\section{MEASUREMENT AND ANALYSIS}

The wireless channel coefficients $\left(S_{21}\right)$ were measured after TRL calibration (Alshabo et al, 2013), with and without the presence of the $2.57 \%$ methane in a multipath environment within the laboratory. The magnitudes of the complex coefficients for the baseline were subtracted from those measured when methane was present in the rubber tubing.

$$
\text { Difference }=\left|S_{21(\text { Methane })}\right|-\left|S_{21(\text { Baseline })}\right|
$$

The setup is shown in Figure 2. The frequency was varied between $0.3 \mathrm{GHz}$ and $8 \mathrm{GHz}$. There were 1601 discrete frequencies used in the measurements (the largest number of samples that the VNA used was capable of taking). The experiment was repeated ten times for both the baseline and the methane.

Figure 3 illustrates the magnitude difference between two baselines measured sequentially to each other. Note that the resultant trace is almost zero except for some noise around 7 to $8 \mathrm{GHz}$. It suggests that the null hypothesis of nitrogen gas affecting the methane measurements result is low. Figure 4 indicates a snapshot trend of the first magnitudes of the channel coefficients $\left(S_{21}\right)$ for the baseline measurement and the methane measurement. This indicates that there has been a change in the complex channel coefficients over the frequency range from about $1.5 \mathrm{GHz}$ to $8 \mathrm{GHz}$. There was no noticeable difference below $1.5 \mathrm{GHz}$. After $1.5 \mathrm{GHz}$ there are clear differences between the magnitude spectra as shown in Figure 4. These snapshots were repeated nine times for the baseline and ten times for the methane. Figure 5 shows the absolute difference between complex channel coefficients of methane and baseline. The difference was subsequently plotted for five snapshots trends on the same plot. Figure 6, indicates that in the shape of this difference remains consistent over the several repetitions with only minor variation, indicating that the snapshots trends are highly correlated. It should also be noted that the baselines have been changed randomly as well as the methane magnitude channel coefficient traces. Due to the high correlation in shape, we also investigated the variance of the magnitude difference values between 
snapshots. The variance remained essentially constant within a small error. The average value of the variance was found to be $7.7966 \mathrm{e}-05 \pm 5.5008 \mathrm{e}-07$ (using $95 \%$ confidence intervals).

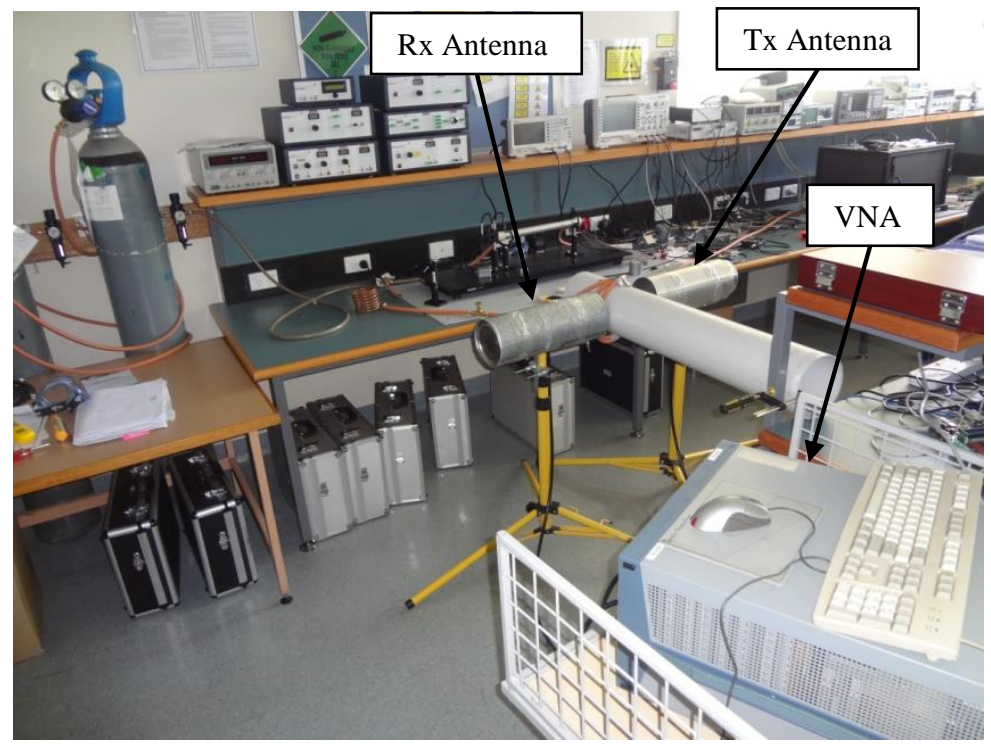

Figure. 1. Experimental setup with 160mm PVC pipe and two turns of the rubber tubing.

Our results shown in Figure 5 indicate that peaks and troughs occurred at various frequencies. This indicates that the methane gas has affected the channel coefficients at various frequencies. Comparing Table 2 to Table 1 , we find a repeatable, highly correlated response for the ultra wideband channel through methane gas at the same frequency values, we found more peaks, which indicate that the methane gas has been affected more through the use of Ultra wideband channel frequency measurements. These are peaks shown in Figure 5.

TABLE2: DIFFERENT PEAKS AT DIFFERENT FREQUENCIES

\begin{tabular}{|c|c|}
\hline Frequency in GHz & Amplitude \\
\hline 1.561 & $0.3811 \mathrm{e}-2$ \\
\hline 1.792 & $0.6623 \mathrm{e}-2$ \\
\hline 2.514 & $-0.2024 \mathrm{e}-2$ \\
\hline 2.687 & $-0.5653 \mathrm{e}-2$ \\
\hline 2.7746 & $-1.35 \mathrm{e}-2$ \\
\hline 3.943 & $-0.5896 \mathrm{e}-2$ \\
\hline 4.607 & $0.648 \mathrm{e}-2$ \\
\hline 5.002 & $1.081 \mathrm{e}-2$ \\
\hline 5.17 & $0.6947 \mathrm{e}-2$ \\
\hline 6.941 & $0.6259 \mathrm{e}-2$ \\
\hline 7.466 & $0.07224 \mathrm{e}-2$ \\
\hline
\end{tabular}




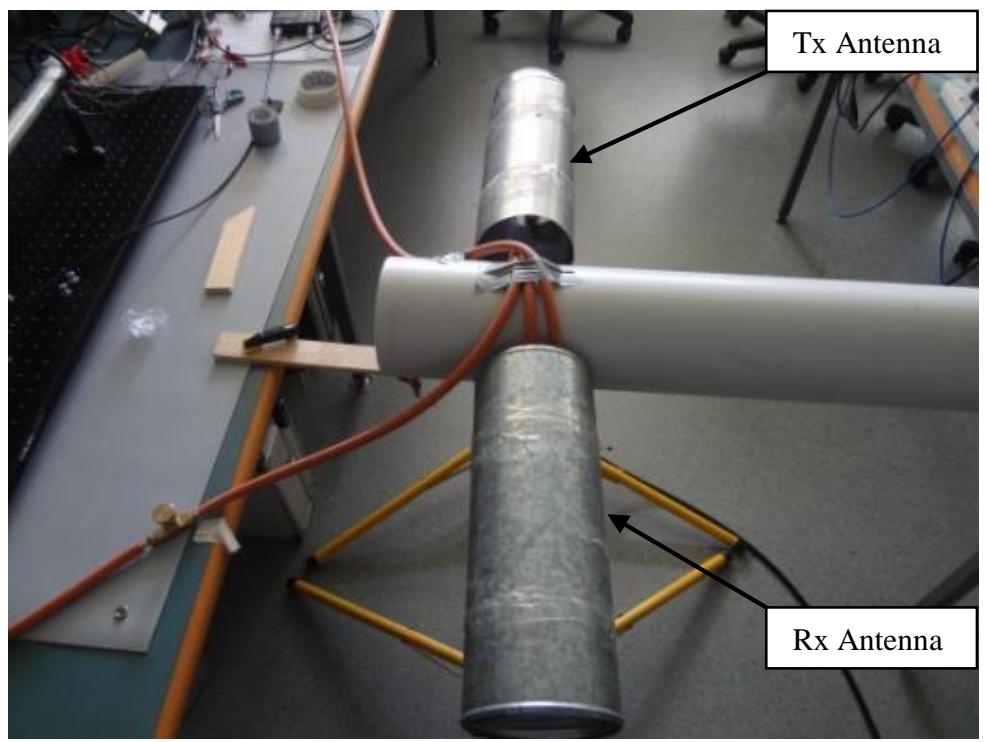

Figure. 2 Experimental setup with 160mm PVC pipe and two turns of the rubber tubing

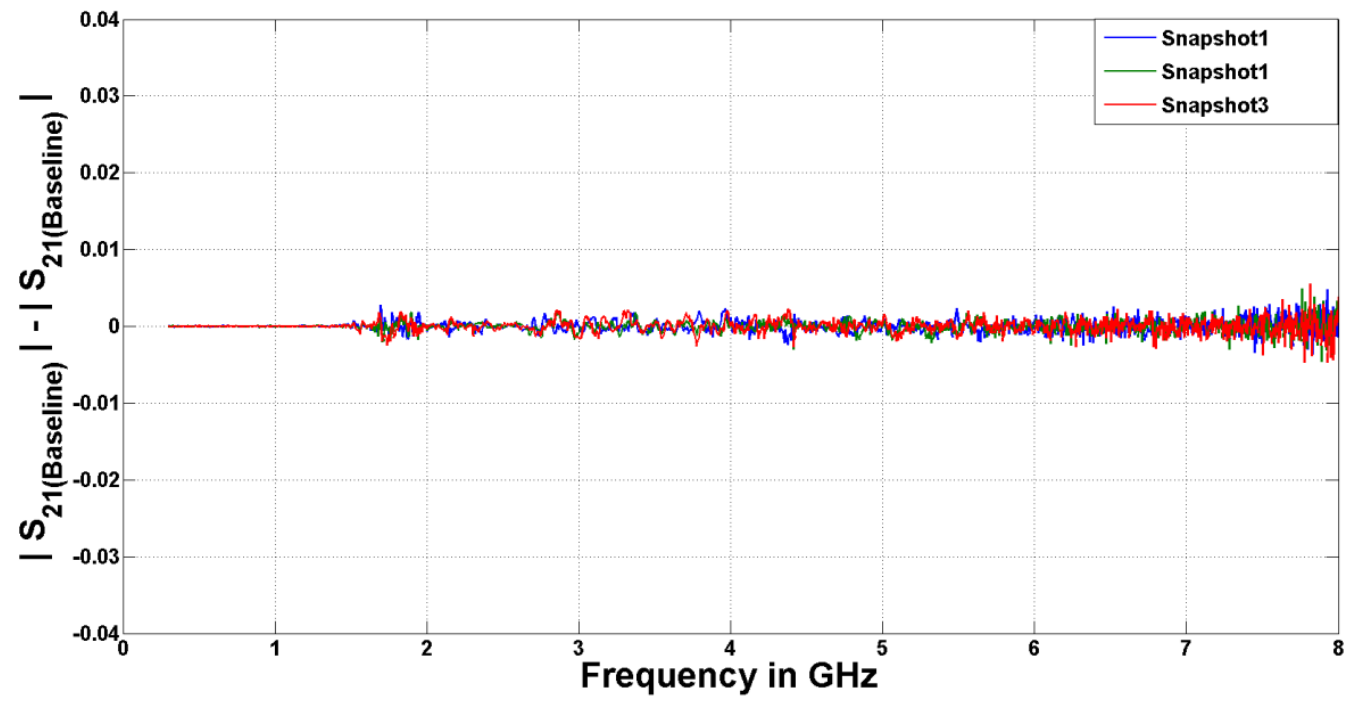

Figure. 3 Three absolute differences between two baseline snapshots superimposed on each other showing the same shape with small variation for each snapshot for $160 \mathrm{~mm}$ PVC pipe. 


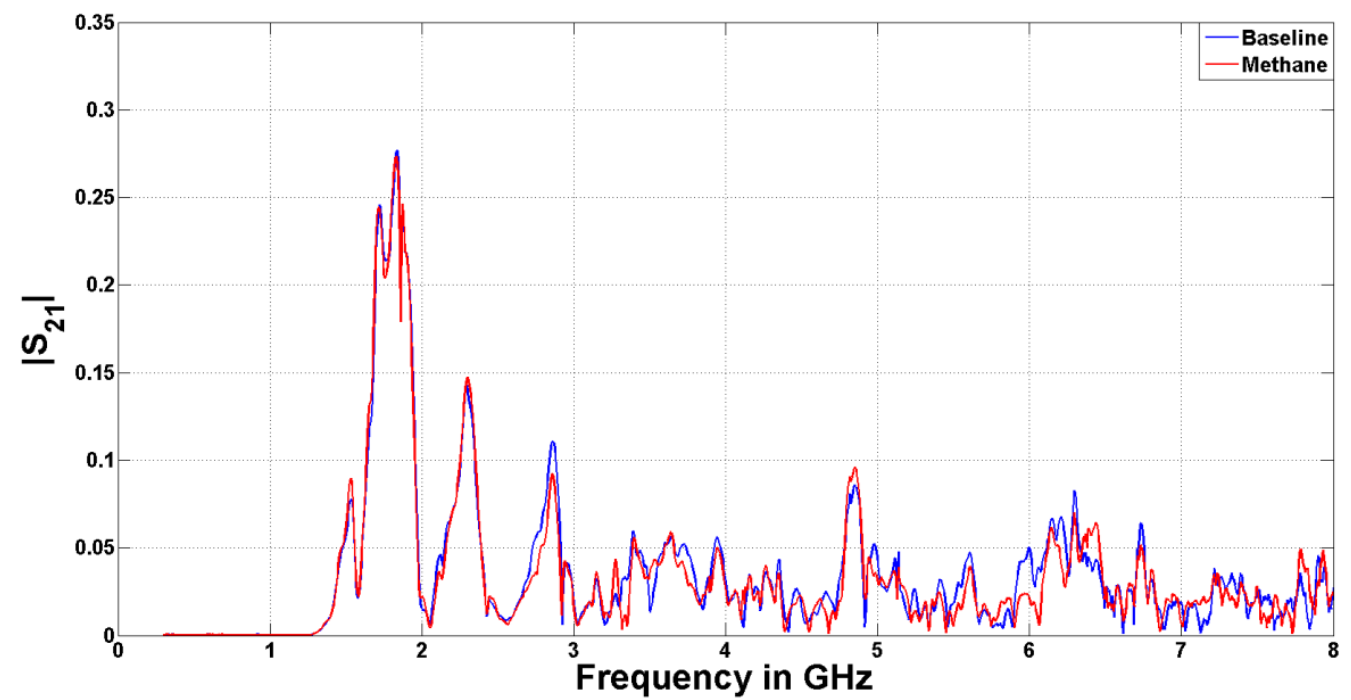

Figure. 4 A single snapshot trend of the channel coefficients for baseline and methane.

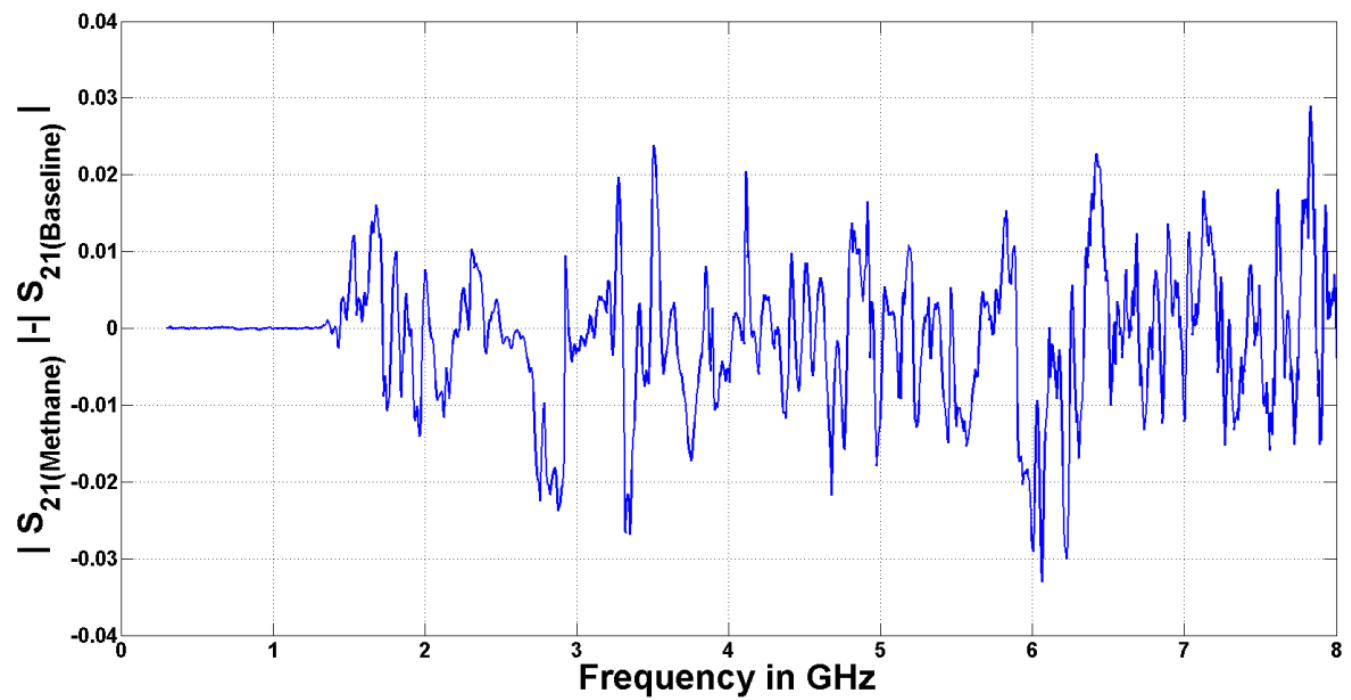

Figure. 5 Absolute difference between methane and baseline. 


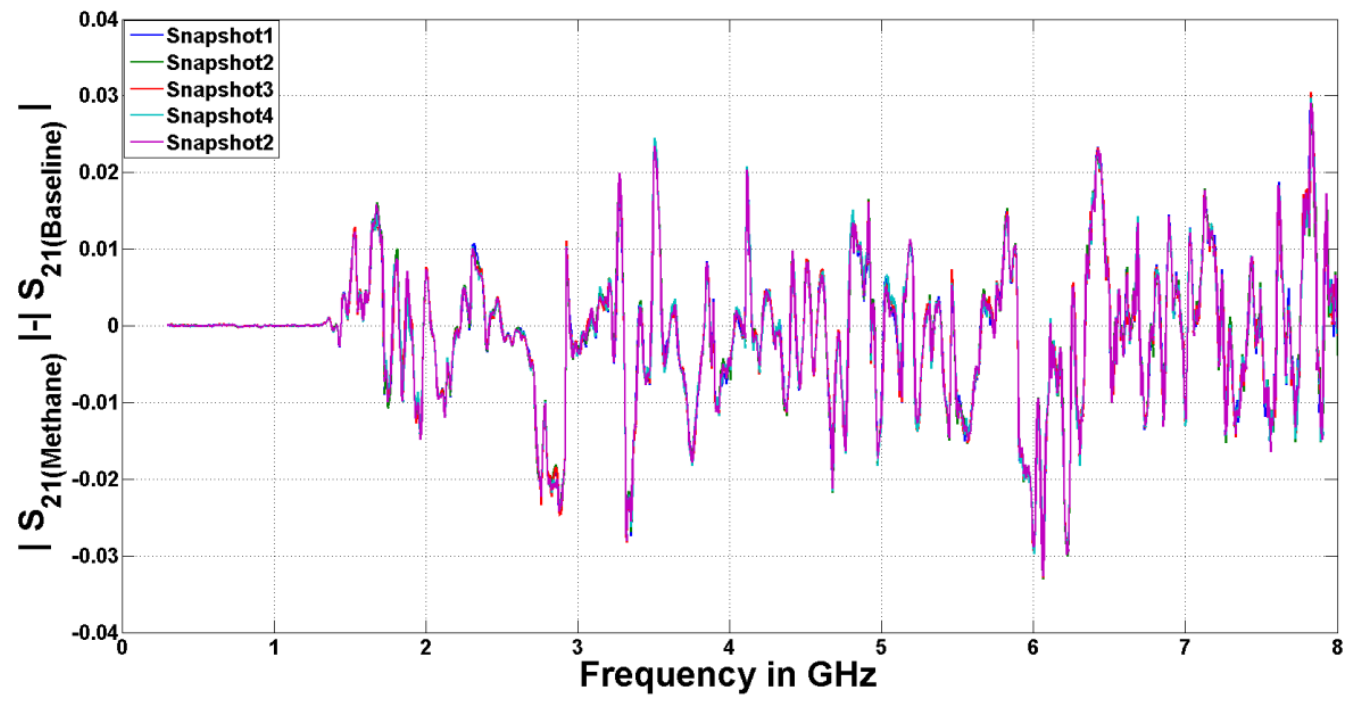

Figure. 6 Five absolute differences between methane and baseline trends superimposed on each other showing the same shape with small variation for each snapshot for $160 \mathrm{~mm}$ PVC pipe.

\section{CONCLUSION}

We have measured consistent but varying channel coefficients shape differences over different frequency ranges. For a particular frequency range we found the shape of the difference magnitude between baseline and methane measurements varied significantly. The shape of the resultant magnitude difference spectra remained very nearly constant and these differences obtained almost the same variance. We found a number of peaks of the variations that indicate that the methane gas can have a measurable effect on the UWB Channel coefficients for an indoor environment. This study suggests a possible application of this technique to industrial mining activities. This technique could be used to determine the presence of non-explosive levels of methane for situations where methane builds up gradually in a confined or enclosed area. To do this one would need to measure a baseline reference at a time when methane levels are known to be low (possibly after a system has been vented with fresh air). The system then takes continuous measurements of the channel coefficients over the same frequency span. When the variance reaches a threshold level (say, the variance we measured for $2.57 \%$ in the $160 \mathrm{~mm}$ pipe) an alarm could be activated to indicate, the area should be evacuated. Future work could be to apply more sophisticated signal processing algorithms to the difference data to estimate and detect specific concentrations of methane gas.

\section{ACKNOWLEDGEMENT}

The authors would like to thank the University of Southern Queensland for providing access to gases and scientific measurements equipment.

This research has been conducted with the support of the Australian Government research Training Program Scholarship

\section{REFERENCES}

Alshabo, A., Stirling, D., Ros, M., Vial, P., Wysocki, B. \& Wysocki, T. 2014. "An approach to Ultra Wideband Channel Calibration using a Vector Network Analyzer". Australian Journal of Elctrical \& Electronics Engineering.

Alshabo, A., Stirling, D., Ros, M., Vial, P. J., Wysocki, T. A. \& Wysocki, B. J. Year. "UltraWideband wireless channel in presence of atmospheric gases and refined engine oil". In: Signal Processing and Communication Systems (ICSPCS), 2012 6th International Conference on, 12-14 Dec. 2012 2012. 1-7. 
Baghdady, E. J. \& Ely, O. P. 1966. "Effects of exhaust plasmas upon signal transmission to and from rocketpowered vehicles". Proceedings of the IEEE, 54, 1134-1146.

Boan, J. 2007. "Radio Experiments With Fire". Antennas and Wireless Propagation Letters, IEEE, 6, 411-414.

Leis, J., Buttsworth, D., Snook, C. \& Holmes, G. 2014. "Detection of Potentially Explosive Methane Levels Using a Solid-State Infrared Source". Instrumentation and Measurement, IEEE Transactions on, 63, 3088-3095.

Maryott, A. A. \& Birnbaum, G. 1956. "Microwave Absorption in Compressed Gases; Saturated Hydrocarbons". The Journal of Chemical Physics, 24, 1022-1026.

Micheli, D., Delfini, A., Santoni, F., Volpini, F. \& Marchetti, M. 2015. "Measurement of Electromagnetic Field Attenuation by Building Walls in the Mobile Phone and Satellite Navigation Frequency Bands". Antennas and Wireless Propagation Letters, IEEE, 14, 698-702.

Rossignol, J., Stuerga, D. \& Jouhannaud, J. 2010. "Broadband microwave gas sensor: A coaxial design". Microwave and Optical Technology Letters, 52, 1739-1741.

Selmic, R. R., Mitra, A., Challa, S. \& Simicevic, N. 2010. "Ultra-Wideband Signal Propagation Experiments in Liquid Media". Instrumentation and Measurement, IEEE Transactions on, 59, 215-220.

Shimomura, N., Otsu, M. \& Kajiwara, A. Year. "Empirical study of remote respiration monitoring sensor using wideband system". In: Signal Processing and Communication Systems (ICSPCS), 2012 6th International Conference on, 12-14 Dec. 2012 2012. 1-5.

United State Environmental Protection Agency 2010. Methane and Nitrous Oxide Emissions from Natural Sources. U.S. Environmental Protection Agency. Washington, DC, USA.

Wee, F. H., Soh, P. J., Suhaizal, A. H. M., Nornikman, H. \& Ezanuddin, A. a. M. Year. "Free space measurement technique on dielectric properties of agricultural residues at microwave frequencies". In: Microwave and Optoelectronics Conference (IMOC), 2009 SBMO/IEEE MTT-S International, 3-6 Nov. 2009 2009. 183-187.

Yin-Chung, L. \& Porter, J. 1978. "RF Coverage Analysis and Performance for Shuttle Communication Links". Communications, IEEE Transactions on, 26, 1745-1757. 